\title{
Research Paper \\ Acceptance of Information and Communication Technology by the Elderly People Living in Tehran
}

\author{
Mehdi Basakha ${ }^{1,2}$, *Seyed Hossein Mohaqeqi Kamal ${ }^{1,2} \odot$, Hakimeh Pashazadeh ${ }^{3}$
}

1. Social Welfare Management Research Center, Department of Social Welfare, University of Social Welfare and Rehabilitation Sciences, Tehran, Iran. 2. Iranian Research Center on Aging, University of Social Welfare and Rehabilitation Sciences, Tehran, Iran.

3. Department of Social Work, University of Social Welfare and Rehabilitation Sciences, Tehran, Iran.

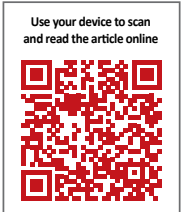

Citration Basakha M, Mohaqeqi Kamal SH, Pashazadeh H. [Acceptance of Information and Communication Technology by the Elderly People Living in Tehran (Persian)]. Salmand: Iranian Journal of Ageing. 2019; 13(Special Issue):550-563. https://doi. org/10.32598/SIJA.13.Special-Issue. 550

d.j" https://doi.org/10.32598/SIJA.13.Special-Issue.550

(a) $0 \%$

Received: 23 Jul 2018

Accepted: 10 Jan 2018

Available Online: 10 Mar 2019

Key words:

Information technology, Self-help devices, Internet, Aging

\section{ABSTRACT}

Objectives Nowadays, Information and Communication Technology (ICT) provides a potential opportunity for communities by changing the concept of distance. Despite the development of communication and information tools and their widespread use, the statistics indicate a digital gap and very low use of these tools by the Iranian elderly. This study aimed to investigate the status of acceptance of ICT and its related factors by elderly people living in Tehran City, Iran.

Methods \& Materials The cross-sectional study was conducted in summer 2018. A sample of 330 elderly people living in Tehran was selected by multistage sampling method. All obtained data were analyzed by the Shapiro-Wilk test, point biserial correlation test, the Spearman correlation test, and the Pearson correlation test in SPSS 21.

Results Most participants belonged to the age range of 60 to 70 years (61\%), were men (67\%), married $(85.5 \%)$, and had a diploma or lower education $(72.5 \%)$. The results show that the most popular ICT among the elderly were watching TV, talking on the phone, and readings news, while sending and receiving emails was the least popular one. The Mean $\pm S D$ technology acceptance score among the elderly was $3.15 \pm 0.75$ which was above its theoretical average (score 3 ). The most important barriers of older people to accept ICT was "lack of interest", "feeling no need", and "lack of familiarity with the ICT tools". Acceptance of technology has been strongly associated with education ( $r=0.325$, $P<0.001)$, age $(r=0.236, P<0.001)$, and available time to use ICT tools $(r=0.528, P<0.001)$. In addition, the acceptance of technology has not been significantly correlated with the general health status of the elderly and their economic situation.

Conclusion The technology acceptance status of older people in Tehran was higher than average and the intention to use ICT tools was significant among them. But the difficulty in using some of these tools has been one of the most important limitations in adopting ICT technologies. Additionally, the adoption of technology among the elderly is not influenced by their economic situation or the health status, and therefore all groups of the elderly can be considered target groups to enhance their ability to use ICT tools.

\section{* Corresponding Author:}

Seyed Hossein Mohaqeqi Kamal, PhD.

Address: Social Welfare Management Research Center, Department of Social Welfare, University of Social Welfare and Rehabilitation Sciences, Tehran, Iran.

Tel: +98 (21) 22180048

E-mail: ho.mohagheghi@uswr.ac.ir 


\section{Extended Abstract}

\section{Objectives}

nformation and Communication Technology (ICT) has radically changed cultural and social issues by changing communication channels [1-3] and providing more communication paths for people. Apart from its interesting nature, ICT has provided services for the elderly which were not previously possible for them. Remote care, telecommunication, ICT-based health services, and online social support are some of the most important services of ICT for promoting health, quality of life, and individual autonomy of the elderly [4-6]. Despite the amazing development and use of various communication and information tools, evidence suggests a digital generation gap and less benefit of older people from these tools. The purpose of this study is to investigate the acceptance of ICT by elderly people living in Tehran, Iran.

\section{Methods and Materials}

This is a cross-sectional study conducted on 330 seniors living in Tehran in 2018. They were selected using a multistage sampling technique. Inclusion criteria were aged 55 years or older and literate, while exclusion criteria were the unwillingness to participate in the study and inability to answer a question. The data collection tool was ICT acceptance questionnaire designed by Basakha and Mohaqeqi [7]. It has 24 items with 5 subscales of independence of user, perceived usefulness, perceived ease of use, attitude to use, and intention to use ICT. In their study, the content validity index of the items ranged between 0.87 and 1 ; and 0.98 for the whole questionnaire. Its structural validity has also been investigated through confirmatory factor analysis. The Cronbach $\alpha$ coefficient for the internal consistency of its subscales was between 0.83 and 0.87 ; and 0.88 for the whole questionnaire [7]. In addition to these questions, there were some other questions about the elders' demographic characteristics, the perception of socio-economic conditions, public health, and time use. There was also a checklist with items assessing ICT-based activities of the participants.

The collected data were analyzed in SPSS V. 21 using statistical tests of Shapiro-Wilk, point biserial correlation, the Spearman correlation, and Pearson correlation. It should be mentioned that this study was approved by the Research Ethics Committee of the University of Social Welfare and Rehabilitation Sciences (Code: IR.USWR.REC.1396.142).

\section{Results}

Most of the participants were male $(97 \%)$, married $(85.5 \%)$, aged between 60 and 70 years $(61 \%)$, with high school diploma or lower education (72.5\%). The most popular ICT tools among elderly people were $\mathrm{TV}$, then the mobile phone, and finally, landline phone. While the tablet was the least common ICT tool among study subjects. Based on the obtained data, $77.9 \%$ of the subjects had smartphones, which is indicative of their potential for the use of an operating system and its services. Watching TV, talking on the phone and reading news were the most common ICT-related activities while sending/receiving emails was the least one. According to the subjects' reports, the most important reasons for not using ICT tools were the lack of need (30.3\%), lack of interest (27\%), and lack of skill (18.5\%).

The Mean \pm SD acceptance score of ICT by the subjects was $3.15 \pm 0.75$ which was higher than the average score of 3. Among dimensions of ICT acceptance, "Intention to use" had the highest score (mean=3.68) while "perceived ease of use" (mean=2.63) had the lowest score. ICT acceptance had a significant correlation with education $(\mathrm{r}=0.325)$, age $(\mathrm{r}=-0.236)$, and the time allocated to use ICT tools $(\mathrm{r}=0.528)$ $(\mathrm{P}<0.001)$. Based on these results, spending more time on using ICT tools and gaining higher educational level have a positive and significant impact on ICT acceptance of the elderly people. Moreover, with the increase of age, ICT acceptance by the elderly people decreases. Gender also had a significant and negative correlation with ICT acceptance $(\mathrm{r}=-0.108, \mathrm{P}<0.05)$. That is, being a woman also affects ICT acceptance. A significant positive correlation was also found between marital status and ICT acceptance $(\mathrm{r}=0.0111, \mathrm{P}<0.001)$, where married seniors accepted ICT more than singles. Finally, results showed that ICT acceptance had no significant correlation with the general health $(\mathrm{r}=0.070, \mathrm{P}=0.212)$ and economic situation $(\mathrm{r}=0.053$, $\mathrm{P}=0.340$ ) of the elders. These variables had correlation only with one dimension (independence of user).

\section{Conclusion}

In the current study, most elderly people had smartphones; this shows their potential for using operating systems on their devices and their services. Watching TV was the most popular activity among the subjects. Therefore, the TV medium can be the best way to develop the ability of the elderly to use other ICT tools. Reminder applications and messengers were popular among the elderly and can be used in personal and social spheres of the old life. The rate of ICT adoption by seniors in Tehran was higher than the average level, and the intention to use ICT tools among 
them was considerable, but the difficulty in use was one of the most important barriers in adopting ICT. Furthermore, acceptance of ICT was not affected by the economic situation or the health status of the elderly. Hence, all elderly groups can be considered as target groups for Improving the ability to use ICT tools.

\section{Ethical Considerations}

Compliance with ethical guidelines

Potential respondents were informed that their participation was voluntary and their collected data were used solely for scientific purposes. The study was approved by the Ethics Committee of the University of Social Welfare and Rehabilitation Sciences (IR.USWR.REC.1396.142).

\section{Funding}

We gratefully acknowledge the financial support of Research and Technology Office of University of Social Welfare and Rehabilitation Sciences (Grant No.96.T.1468).

Authors' contributions

Conceptualization: Mehdi Basakha; Methodology: Mehdi Basakha, Hossein Mohaqeqi Kamal; Investigation: Hakimeh Pashazadeh; Original draft preparation: All authors; and review \& editing: Hossein Mohaqeqi Kamal, Mehdi Basakha.

\section{Conflict of interest}

The authors declared no conflict of interest.

\section{Acknowledgments}

The authors sincerely thank the Research and Technology Office of University of Social Welfare and Rehabilitation Sciences for assisting us in the research. 


\title{
بررسى وضعيت يذيرش تكنولورى ارتباطات و اطلاعات در ميان سالمندان شهر تهران
}

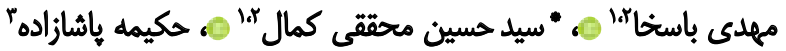 \\ ا - مركز تحقيقات مديريت رفاه اجتماعى، كروه رفاه اجتماعى، دانشكاه علوم بهزيستى و توانبخشى، تهران، ايران.

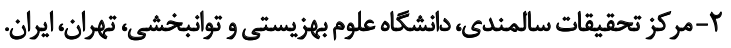

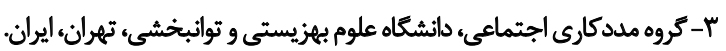

\begin{abstract}
حكند

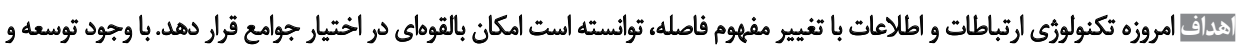

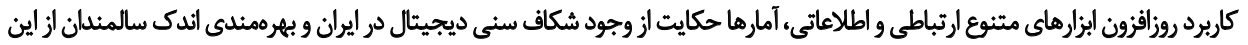

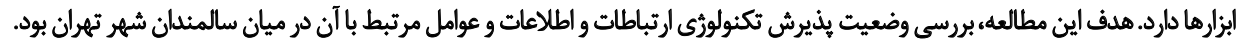

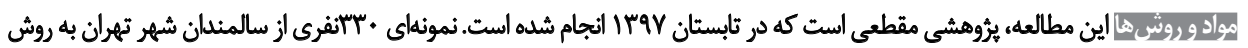

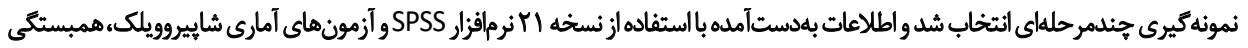

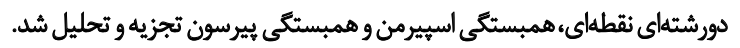

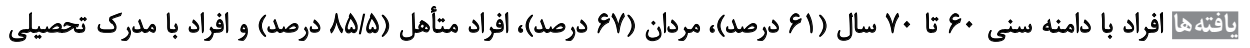

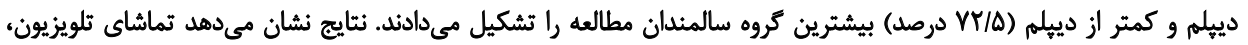

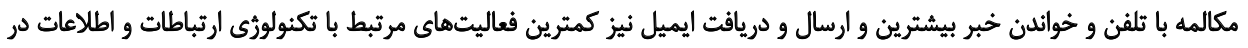

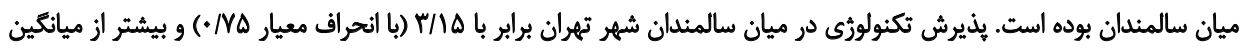

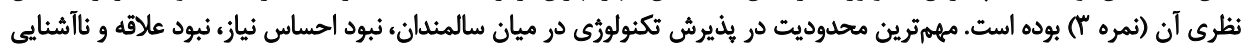

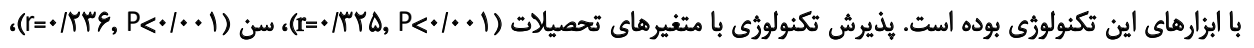

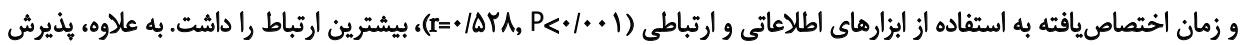

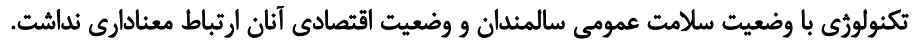

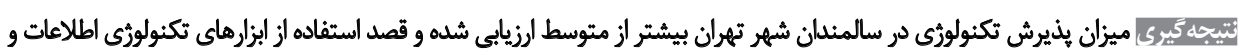

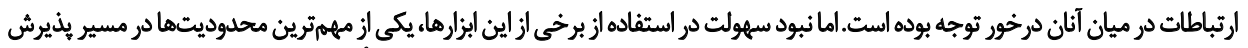

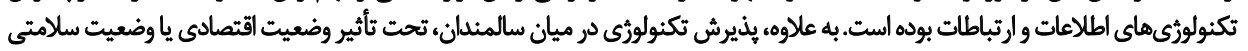

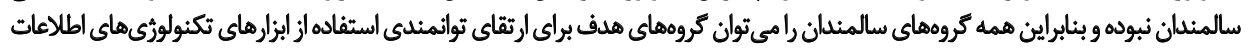

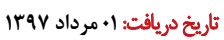

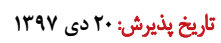
تاريخ انتشار: 199 اسفند

در كنار منافع عمومى اين ابزارها، تكثولوزى اطلاعات و ارتباطات

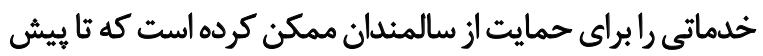

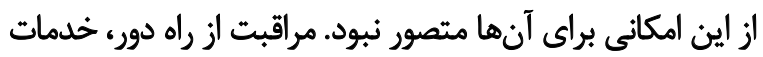

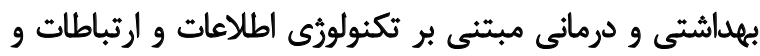

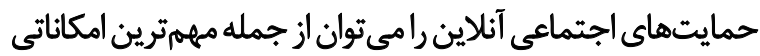

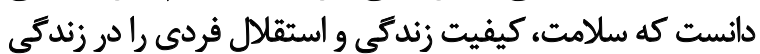

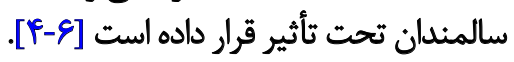
بر اساس اطلاعات مربوط به ميزان استفاده خانوارهاى ايرانى

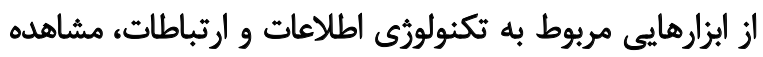

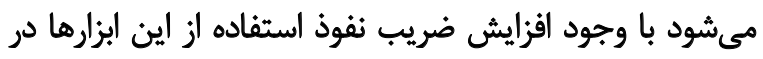

ظهور و گسترش تكنولورىهاى متنوع اطلاعات و ارتباطات، يتانسيل عظيمى رادر اختيار جوامع قرار داده است تا با با استفاده

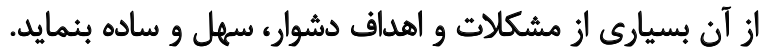

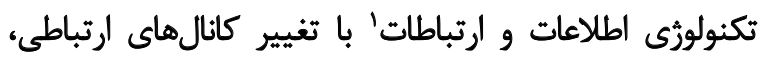

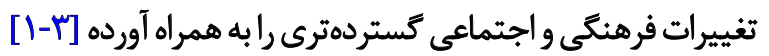

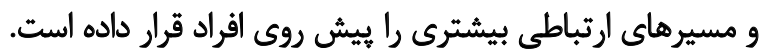

1. Information and Communication Technologies (ICT)

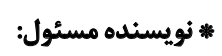

$$
\begin{aligned}
& \text { دكتر سيد حسين محققى كمال }
\end{aligned}
$$

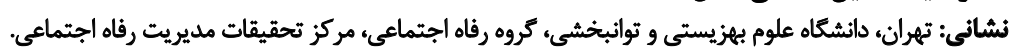

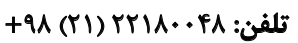

$$
\begin{aligned}
& \text { يست الكترونيكي: ho.mohagheghi@uswr.ac.ir }
\end{aligned}
$$


عواملى است كه نقش تعيينكنندهاي در بذيرش و استفاده از

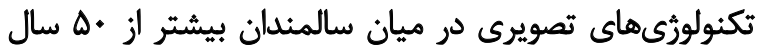

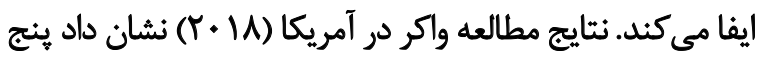

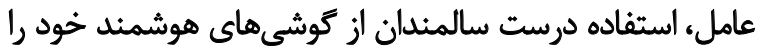

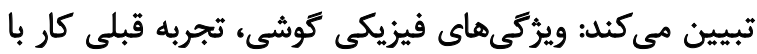

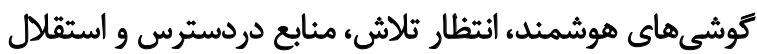

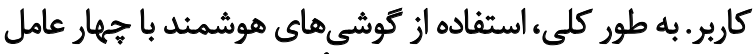

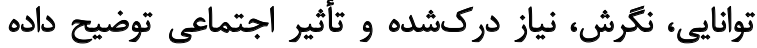

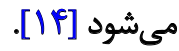

مرور منابع مربوط به عوامل مؤثر بر استفاده از تكنولوزى هائى

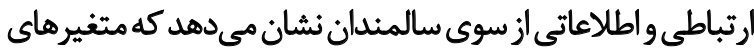
فردى (ماند سطح تحصيلات، وضعيت سلامت، وضعيت

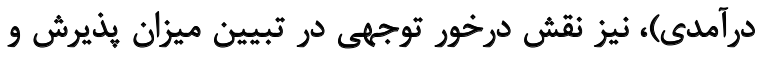

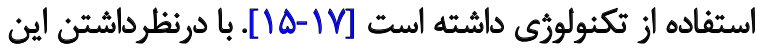

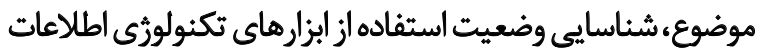

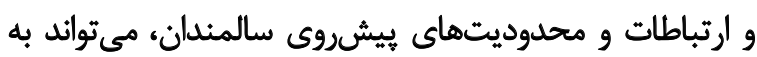

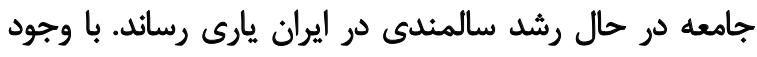

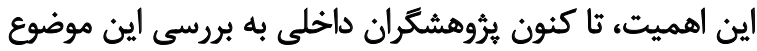

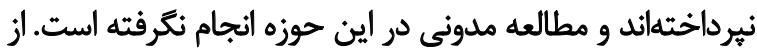

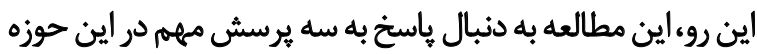

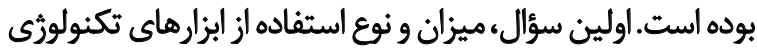

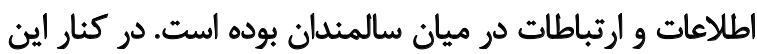

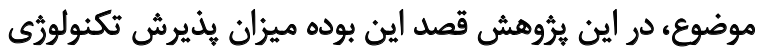

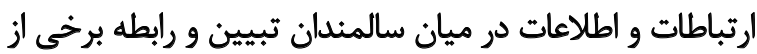

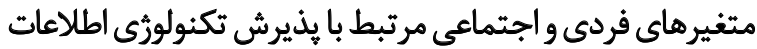
و ارتباطات بررسى شود. ووش مطالعه

اين مطالعه، برُوهشى مقطعى است كه به روش بيمايش در

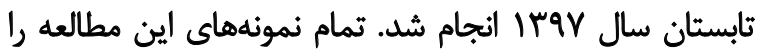

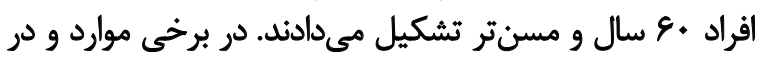

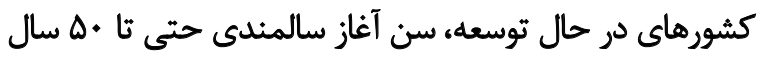

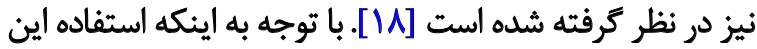

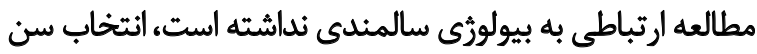

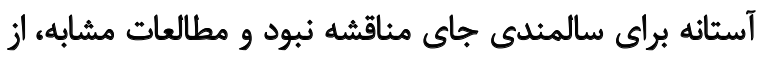

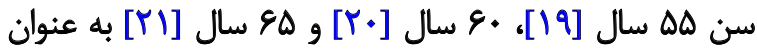

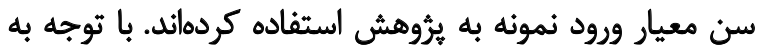

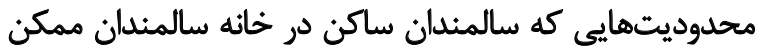

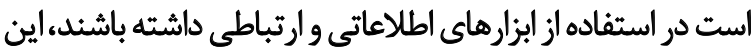

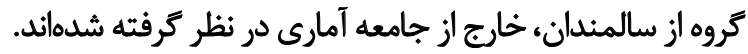

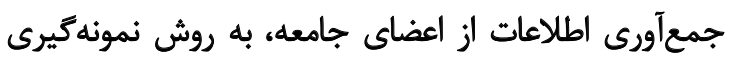

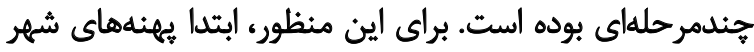

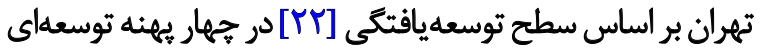

ميان كروههاي سنى مختلف، اين رشد براي گروههاى سنى بالا،

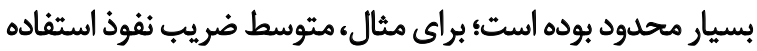

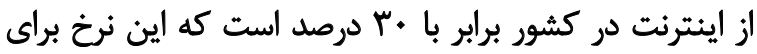

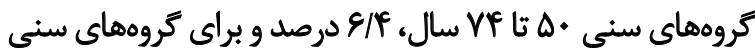

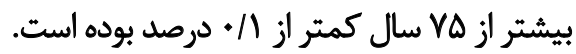

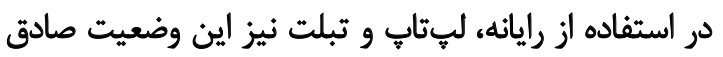

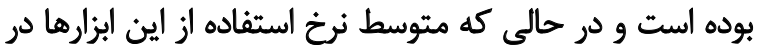

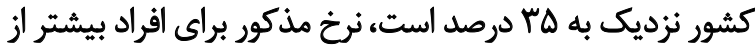

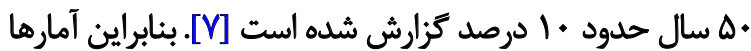

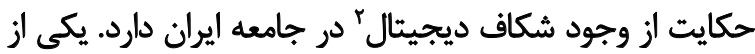

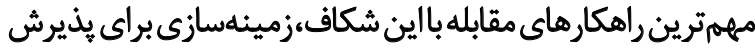

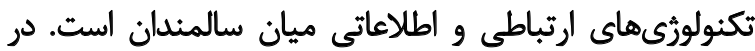

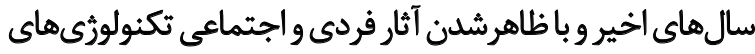

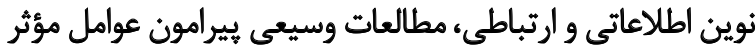

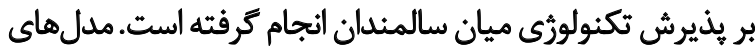

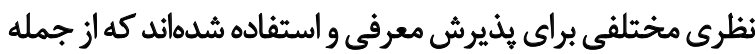

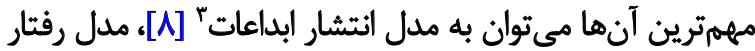

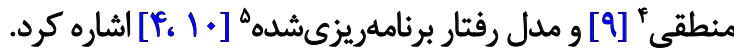

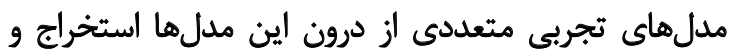

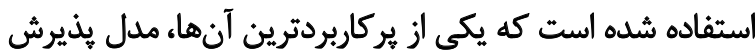

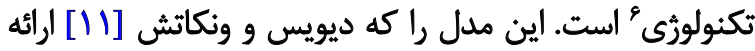

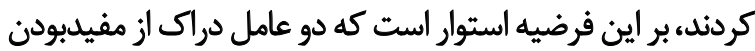

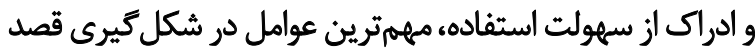

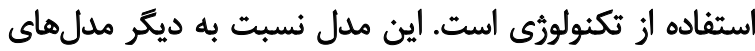

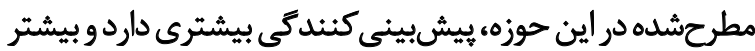

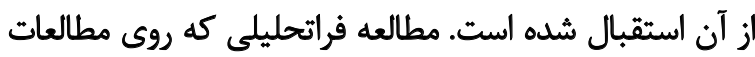

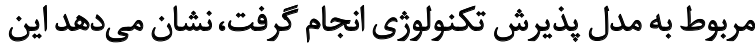

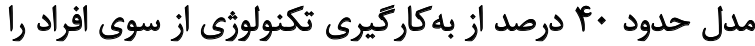

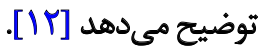

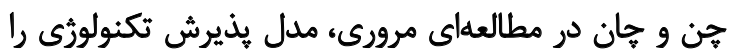

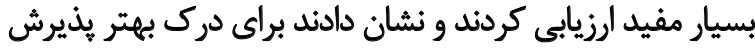

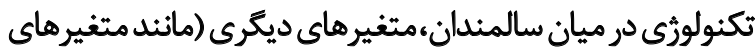

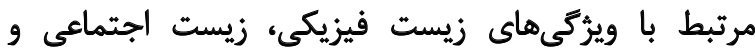

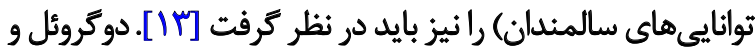

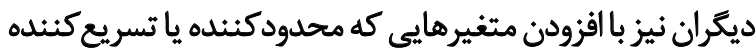

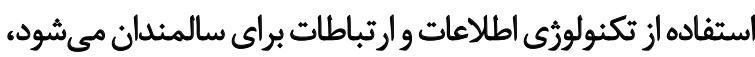

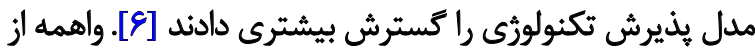
تكنولورىى، سودمندى و تجربه و تبحر در استفاده از تكنولئي

\section{Digital gap}

3. Diffusion of innovations

4. Theory of reasoned action

5. Theory of planned behavior

6. Technology Acceptance Model (TAM) 
درصد و دقت /A/ • معادل يكينجمه واريانس)، تعداد 9 •ب نفر

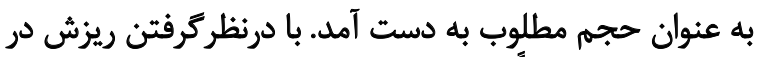

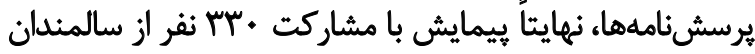

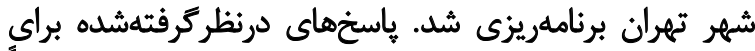

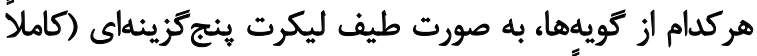

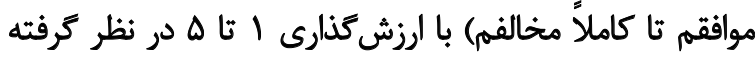

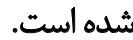

در كنار سؤالات جمعيتشناختى از سالمندان بيرامون ارزيابى

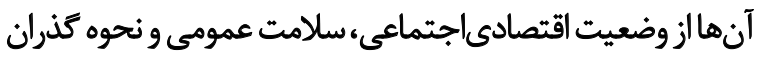

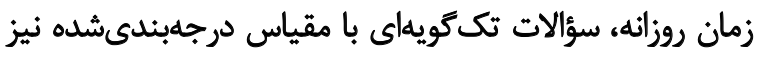

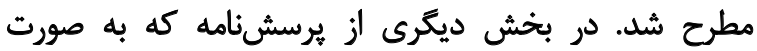

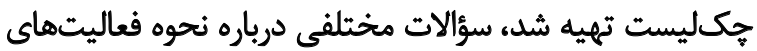

مرتبط با تكنولورى اطلاعات و ارتباطات سالمندان تعبيه شده.

به منظور بررسى رابطه ميان بذيرش تكنولورى و متغيرهاى

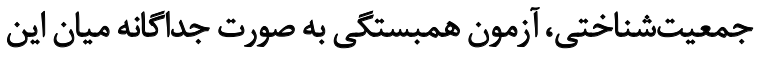

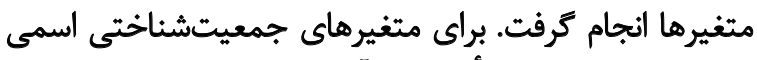

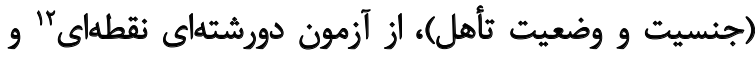

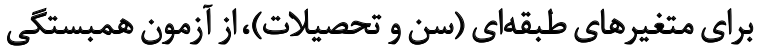

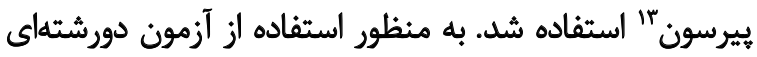

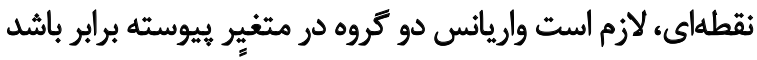

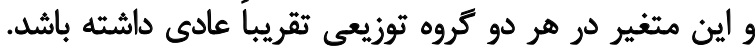

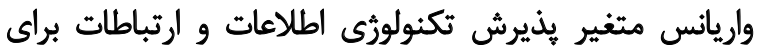

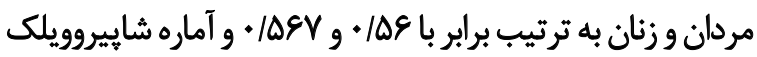

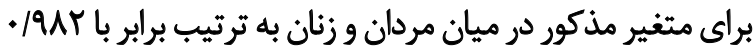

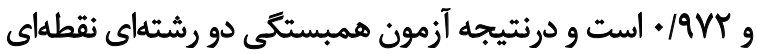

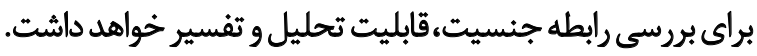

واريانس يذيرش تكنولورى اطلاعات و ارتباطات در سالمندان

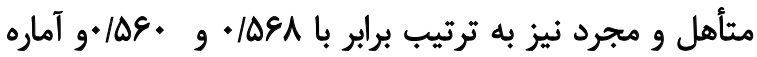

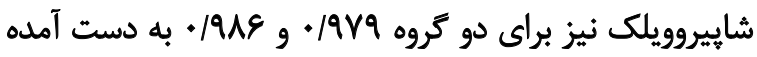

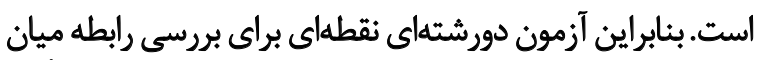

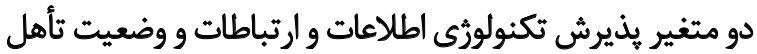

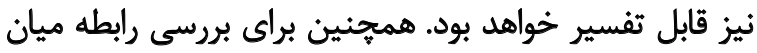

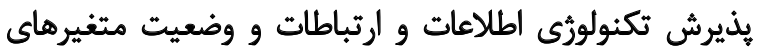

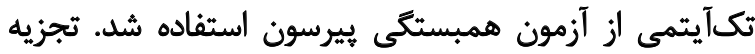

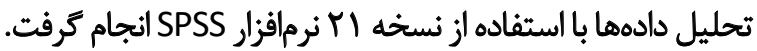

يافتهها

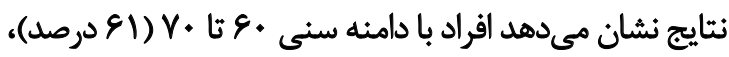

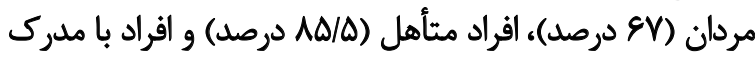

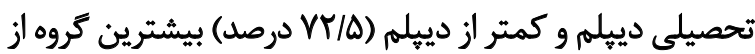

12. Point biserial correlation test

13. Spearman correlation test
طبقلبندى شدند. در مرحله اول نمونهكيرى، يك منطقه از هر

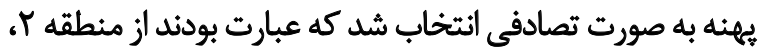

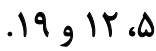

سيس محلات اين مناطق تعيين و مجدداً بر اساس انتخاب

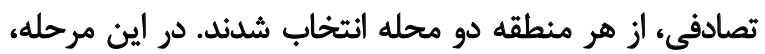

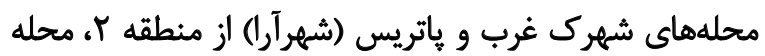

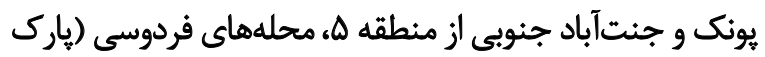

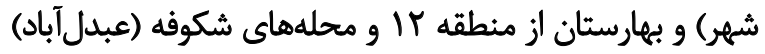

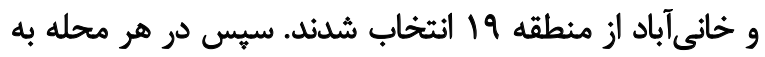

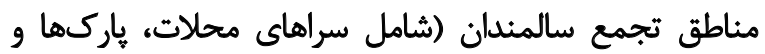

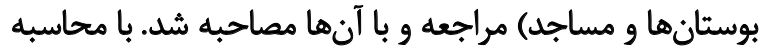

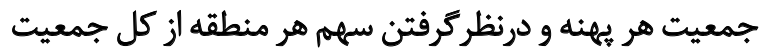

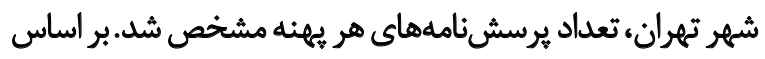

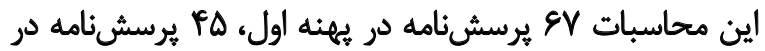

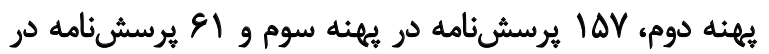

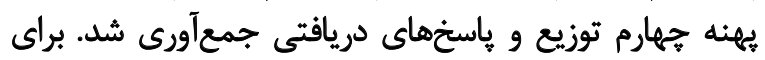

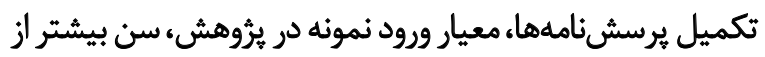

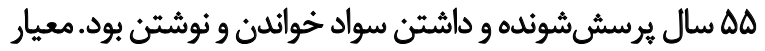

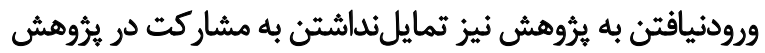

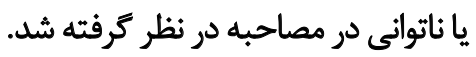

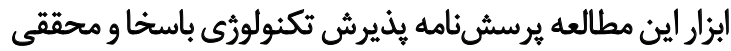

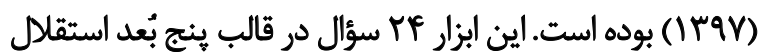

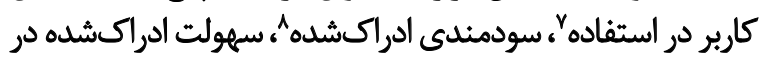

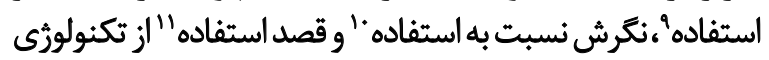

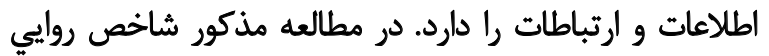

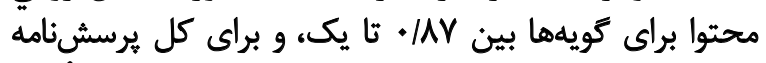

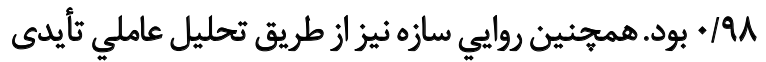

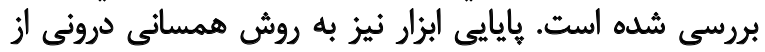

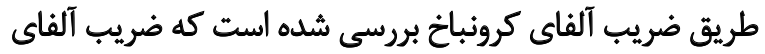

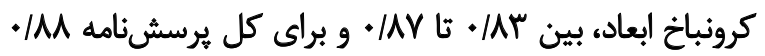

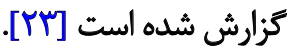

در اين مطالعه اين ترسشنامه در اختيار • ب نفر از سالمندان

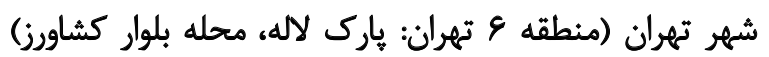

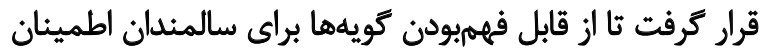

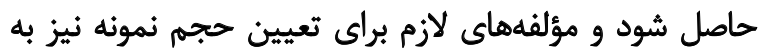

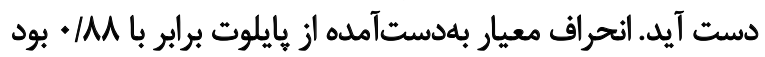

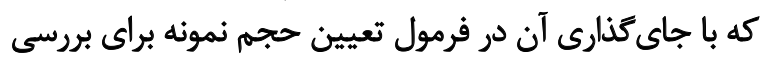

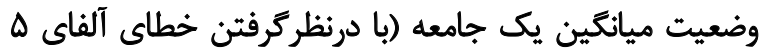

\footnotetext{
7. Independence of user

8. Perceived usefulness

9. Perceived ease of use

10. Attitude to use

11. Intention to use
} 
جدول ا. وضعيت متغيرهاي جمعيتشناختى سالمئدان مطالعه

\begin{tabular}{|c|c|c|c|}
\hline درصد فراواثى & فراوائى & & \\
\hline $8 / 10$ & $r \cdot r$ & g.-89 & \multirow{4}{*}{ سن } \\
\hline YNT & $9 \%$ & $r+-v a$ & \\
\hline 1.1. & $r$ & $1 \cdot-19$ & \\
\hline$\cdot / \mu$ & 1 & .q و بيشتر & \\
\hline SV/E & זוז & مرد & \multirow[b]{2}{*}{ جنسيت } \\
\hline$M T / F$ & $1+\gamma$ & $\dot{j}$ & \\
\hline t/F & $\wedge$ & مجرد & \multirow{3}{*}{ وضعيت تأهل } \\
\hline$A \Delta / T$ & YAI & مثأهل & \\
\hline $\mid r / 1$ & f. & هثناركه يا فوت & \\
\hline$r g / p$ & ir. & كمتر از دييلم & \multirow{5}{*}{ تحصيلات } \\
\hline rg/ & 119 & دييلم & \\
\hline$|r /|$ & P. & كاردانيى & \\
\hline I & $p$ & كارشناسى & \\
\hline $1 / 1$ & 8 & بيشتر از كارشناسى & \\
\hline
\end{tabular}

سالمندان رالز نظر شاخصهاى جمعيتشناختى تشكيل دادهاند مرتبط با ابزارهاى تكنولوزى اطلاعات و ارتباطات در ميان

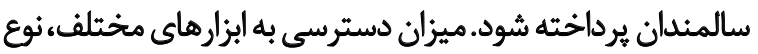

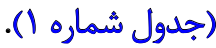

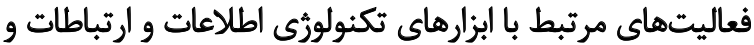

در بخش ديكر ابزار يثوهش، سعى شد تا به بررسى فعاليتهاى

جدول ؟. استفاده سالميدان از ابرًارهاي مختلف اطلاعاتى و ارتباطى (نمونه •بr نفر)

\begin{tabular}{|c|c|c|}
\hline دروصد فراوانى & 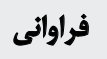 & ابزارهاي اطلاعاتى و ارتباطى \\
\hline$\Delta \mu \%$ & $r M^{\varphi}$ & ت مثلويزيون \\
\hline$W / q$ & rAV & كوشى هوشمند موبايل \\
\hline$\Delta \cdot 18$ & IEV & تلفن ثابت \\
\hline$r q / 1$ & lat & 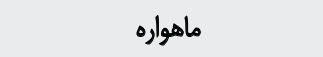 \\
\hline$r+11$ & ITr & 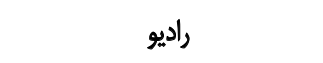 \\
\hline$r \cdot 1 \cdot$ & 88 & يخش هوسيقى \\
\hline $1 \cdot \pi$ & $m$ & كامييوتر \\
\hline $1.1 \%$ & $\pi$ & لي ليتاب \\
\hline$\Delta / r$ & iv & ويدئو \\
\hline$r / V$ & 9 & تبلت \\
\hline
\end{tabular}


جدول r. ميزان فعاليتهاى مرتبط با تكنولوزىهاي اطلاعاتى و ارتباطى در ميان سالمندان (نمونه •بr نفر)

\begin{tabular}{|c|c|c|}
\hline درصد فراوانى & فراوانى & فعاليت با إبزارهاى اطلاعاتى و ارثباطى \\
\hline$\Delta F / F$ & rA. & 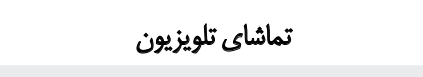 \\
\hline$v e / f+$ & raY & صحبت با تلفن يا موبايل \\
\hline$m q / f$ & ir. & 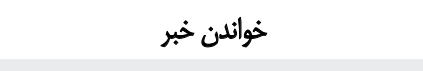 \\
\hline rNA. & ITr & كوش كردن به راديو \\
\hline$m e N$ & $|r|$ & يادآورى برثامهها با موبايل \\
\hline$r \cdot / q$. & $1 . r$ & استفاده از ييامر سانها \\
\hline$r \cdot / q$ & $1 . r$ & ارسال ييامك \\
\hline$r \Delta / \Delta$. & NF & عكاسى با موبايل \\
\hline$M F / Y$. & A. & استفاده از برئامههاي آموزشى و علمى \\
\hline$r M / r$. & V. & كوش كردن به موسيقى \\
\hline$W /$. & er & بانكدارى الكترونيك \\
\hline$I V / T^{*}+$ & $\Delta V$ & جستوجو در اينترنت \\
\hline$i f / Y$. & pV & استفاده از شبكههاى مجازى \\
\hline $1 . / 9$. & rq & 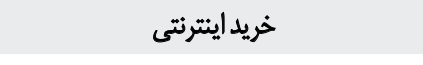 \\
\hline$V / \pi \cdot$ & $r$ & بازئ و سركرمى \\
\hline$\Delta / r$ & IV & 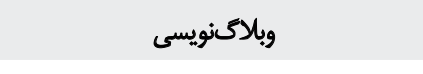 \\
\hline$r / A$ & 18 & مسيريايى \\
\hline$r / \Delta$ & 10 & تايِي و ويرايش متن \\
\hline$\varphi / \Delta$ & 10 & ارسال و دريافت ايميل \\
\hline
\end{tabular}

24

منبع: يافتهاى تحقيق (جمع فراوانى مىتواند بيش از تعداد نمونه و درصد تجمعى بيش از . . الدرصد باشد).

ارتباطات، تماشاي تلويزيون بيشترين فعاليت سالمندان بوده

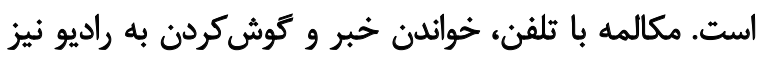

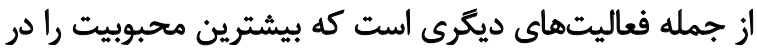

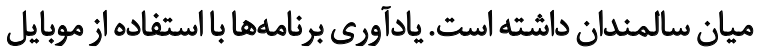
فعاليتى رايج در ميان سالمندان بوده است.

با توجه به اين موضوع مي توان از آن در بهرهمندى از طراحي وني

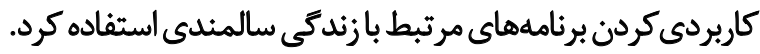

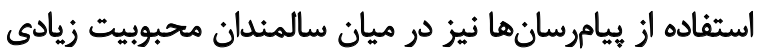

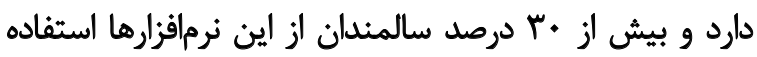

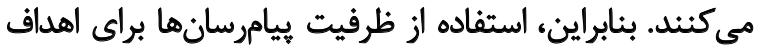

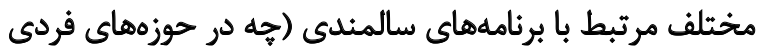

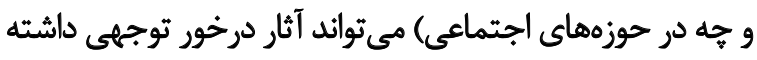

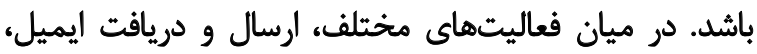
كمترين ميزان كاربرد راد در ميان سالمندان داشته است (جدول
محدوديتهايي كه سالمندان در مسير استفاده از اين ابزارها با

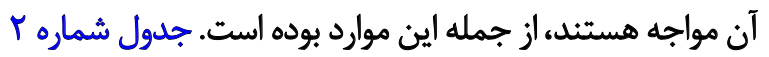

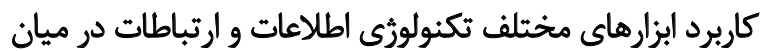

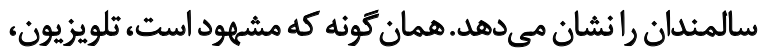

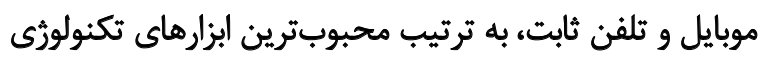

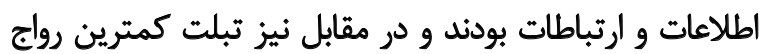

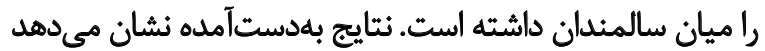

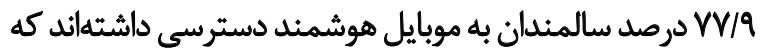

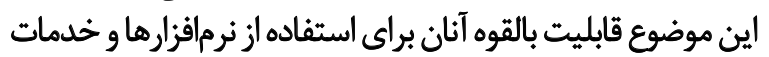

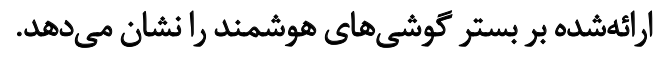

در كنار بررسى وضعيت استفاده از ابزارهاى مختلف تكنولوزى

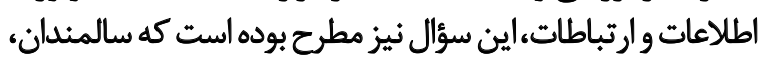

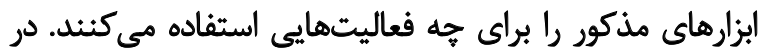

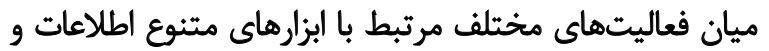


جدول F. نمره يرسششوندكان در يذيرش تكنولوزى و هركدام از ابعاد آن

\begin{tabular}{|c|c|c|c|c|c|}
\hline حداقل - حداكثر نظرى & حداقل -حداكثر نمره دريافتى & 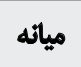 & انحراف معيار & مياتكين & 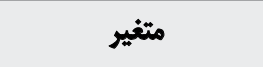 \\
\hline $1-\infty$ & $|/| Y-\varphi / Q T$ & $r / r$. & . Na & $r / 1 \Delta$ & لئيرش تكنولوزى \\
\hline $1-\Delta$ & $1-\Phi$ & $r / T \Delta$ & $1 / 1$ & $r / M$ & خودكارآمدى \\
\hline $1-\Delta$ & $1-Y / N \Delta$ & $r / \Delta$. & $\cdot M$ & $r / R_{T}$ & ادراك از سهولت در استفاده \\
\hline $1-\Delta$ & $1-\Delta$ & $r / f$. & $1 / \cdot 1$ & $r / M$ & ادراك از سودمثلىى \\
\hline $1-8$ & $1-8$ & $r / \pi$. & - /Ar & r/l & كرايش به استفاده \\
\hline $1-\infty$ & $1-\Phi$ & $f \%$. & $1 / 10$ & r/gA & قصد استفاده \\
\hline
\end{tabular}

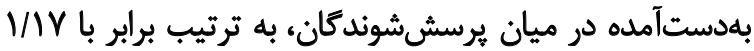

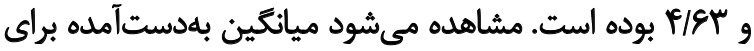
يذيرش تكنولوزى اطلاعات و ارتباطات بيشتر از ميانكين نظرى مئري

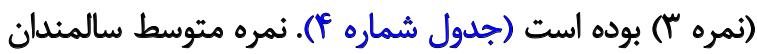

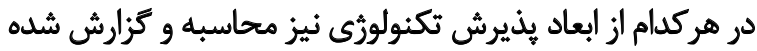

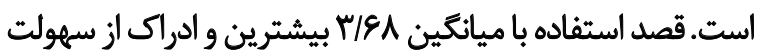

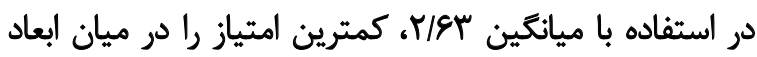
مختلف يذيرش تكنولورى اطلاعات و ارتباطات كرفتهاند.

نتايج بهدستآمده نشان مى دهد بذئيرش تكنولوزى ارتباطات

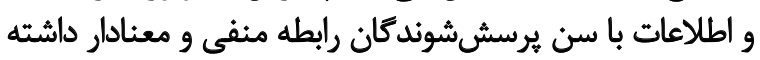

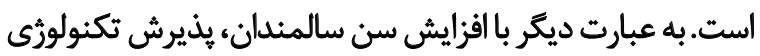

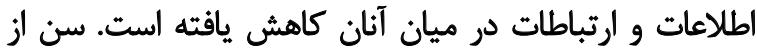

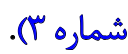

از سالمندان شهر تهران درباره علل استفادهنكردن از ابزرارهاي

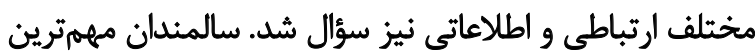

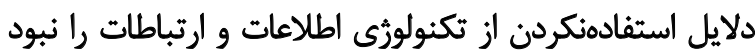

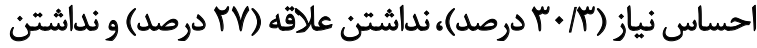
مهارت (N/A ال درصد) عنوان كردماند.

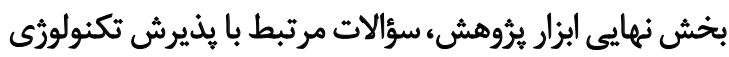

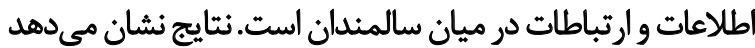

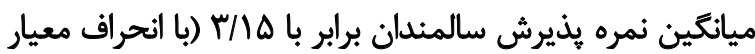

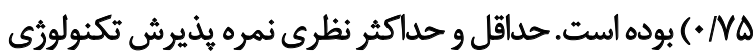

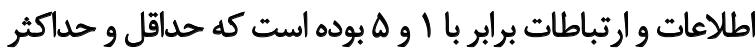

جدول هـ رابطه ميان متغيرهاى جمعيتشناختى با يذيرش تكنولورى و ابعاد آن

\begin{tabular}{|c|c|c|c|c|}
\hline (دورشتهايى نقطاهاى) & تحصيلات) & (دور شتشايى نقطهاي) & (اسييرمن) & 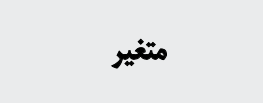 \\
\hline $\begin{array}{c}\cdot / 111^{*} \\
(\mathrm{P}<+1 \cdot+1)\end{array}$ & $\begin{array}{l}. / T Y D^{* *} \\
(\mathrm{P}</ . \cdot \cdot 1)\end{array}$ & $\begin{array}{l}-\cdot / 1 \cdot 1^{*} \\
(* 1+\Delta \cdot)\end{array}$ & $\begin{array}{l}-\cdot / \pi r \% * * \\
(P<\cdot / * \cdot)\end{array}$ & بذيرش تكنولوزى \\
\hline $\begin{array}{c}\cdot / 1 \Delta H^{*} \\
(P<+/ \cdot+1)\end{array}$ & $\begin{array}{l}. / \text { TAPe* } \\
(\mathrm{P}<\cdot / \cdot \cdot+)\end{array}$ & $\begin{array}{l}-. .1 .41 \\
(.18994)\end{array}$ & $\begin{array}{l}-. / \pi+* * \\
(P<\cdot / \cdot \cdot 1)\end{array}$ & خودكارآمدى \\
\hline $\begin{array}{l}\cdot / \cdot \pi r \\
\left(\cdot / R H^{\circ}\right)\end{array}$ & $\begin{array}{l}. / / W W^{* 0} \\
(\mathrm{P}<\cdot / \cdot \cdot 1)\end{array}$ & $\begin{array}{l}. / * N E \\
(\circ / K r)\end{array}$ & $\begin{array}{l}-\cdot / r \cdot r \cdot * \\
(\mathbb{P}<+/ \cdot+)\end{array}$ & دراك از سهولت در استفاده \\
\hline $\begin{array}{l}+/ 1 \% \Lambda^{*} \\
(* / \cdot 11)\end{array}$ & $\begin{array}{l}. / \text { / Y } \\
(\mathrm{P}<\cdot / . . \cdot 1)\end{array}$ & $\begin{array}{l}-+1+\Delta V \\
(\cdot / r+1)\end{array}$ & $\begin{array}{l}-. / 1+9^{\circ} \\
(. / .+4)\end{array}$ & ادراك أز سودمندى \\
\hline $\begin{array}{l}\cdot / \cdot \Delta \Delta \\
(\cdot M T \cdot)\end{array}$ & $\begin{array}{l}. / M+\cdot \cdots \\
(\mathrm{P}<\cdot / \cdot . \cdot 1)\end{array}$ & $\begin{array}{l}-. / 11 \% \Delta^{*} \\
(\cdot / \cdot 1 \Delta)\end{array}$ & $\begin{array}{l}-\cdot / r \cdot r^{* *} \\
(P<\cdot / \cdot \cdot)\end{array}$ & كرايش به استفاده \\
\hline $\begin{array}{l}\% \cdot V A \\
(. / N V V)\end{array}$ & $\begin{array}{l}. / \text { TAPOE } \\
(\mathrm{P}<\cdot / \cdot . \cdot 1)\end{array}$ & $\begin{array}{l}-. / . \vee 1 \\
(\cdot / 19 T)\end{array}$ & $\begin{array}{l}-\cdot / \pi T A^{* *} \\
(P<+/ * \cdot)\end{array}$ & قصد استفاده \\
\hline
\end{tabular}


جدول و. رابطه ميان ويزٔى هاى فردى با يذيرش تكنولوزى و ابعاد آن

\begin{tabular}{|c|c|c|c|}
\hline زمان استفاده از ICT & وضعيت اقتصادى & وضعيت سلامتى & متغير \\
\hline $\begin{array}{c}+/ \Delta A^{* *} \\
(\mathrm{P}<+/ *+1)\end{array}$ & $\begin{array}{l}* / * \Delta r \\
(* / M f *)\end{array}$ & $\begin{array}{l}. / * V \cdot \\
(* / r i r)\end{array}$ & لخأيرش تكنولوزى \\
\hline $\begin{array}{c}. / P \wedge q^{* *} \\
(\mathrm{P}<+/ * 1)\end{array}$ & $\begin{array}{l}. / 1.9 * \\
(. /+41)\end{array}$ & $\begin{array}{l}. / 1 r \sigma^{*} \\
(* / * r \cdot)\end{array}$ & خودكارآمدى \\
\hline $\begin{array}{l}+/ \text { preme* } \\
(P<+/ *+1)\end{array}$ & $\begin{array}{l}.1 .95 \\
(.1 .98)\end{array}$ & $\begin{array}{l}-+1 \cdot 14 \\
(* / 119)\end{array}$ & ادراك أز سهولت در استفاده \\
\hline $\begin{array}{l}+/ 410^{* *} \\
(P</ *+1)\end{array}$ & $\begin{array}{l}+/ 0+r \\
(+/ 4 T)\end{array}$ & $\begin{array}{l}+1+80 \\
(\cdot / \pi 41)\end{array}$ & ادراك از سودمندى \\
\hline $\begin{array}{c}+/ f^{\epsilon}+r^{* *} \\
(P<+/ *+1)\end{array}$ & $\begin{array}{l}+1+4 \mid \\
(+/ 484)\end{array}$ & $\begin{array}{l}. / * 4 V \\
(* / \% q 4)\end{array}$ & كرايش به إستفاده \\
\hline $\begin{array}{l}. / \text { RTY"* } \\
(\mathrm{P}<. / .+1)\end{array}$ & $\begin{array}{l}.10 .8 \\
(. / 941)\end{array}$ & $\begin{array}{l}. / * q 9 \\
(* / r M)\end{array}$ & قصد أستفاده \\
\hline
\end{tabular}

خودكارآمدى و ادراك از سودمندى با تأهل برقرار بوده است. علاوه بر متغيرهاى طبقهاي جمعيتشناختى، وضعيت

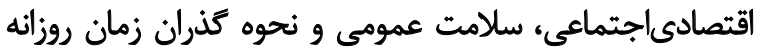

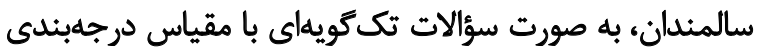

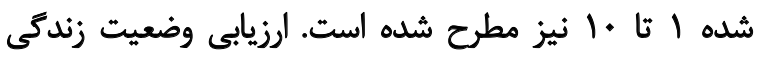

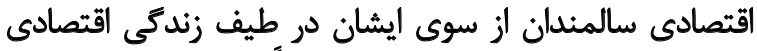

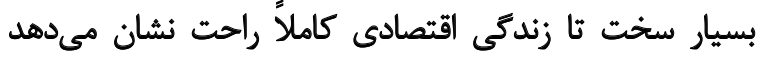

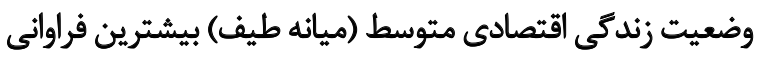

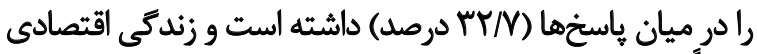

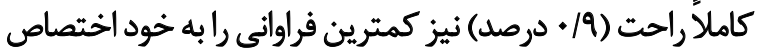

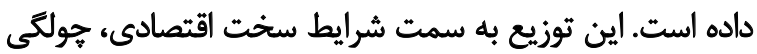
داشته است.

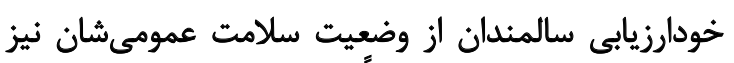

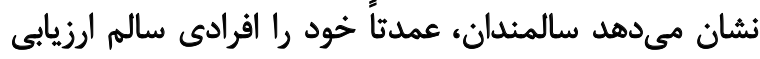

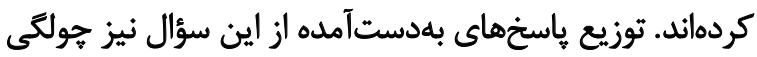

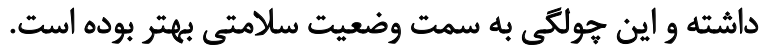

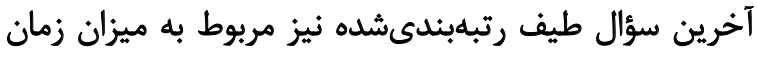

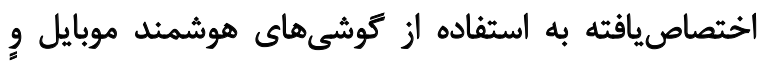

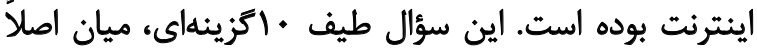

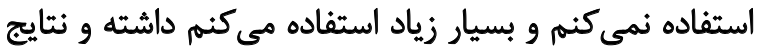

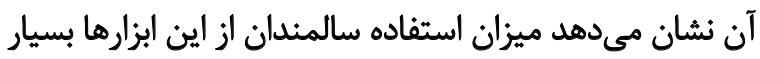

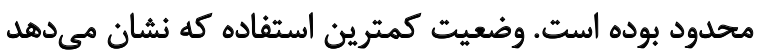

جمله متغيرهايى بوده است كه رابطه معنى دار و قوى آى با ابعاد

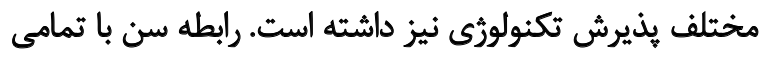

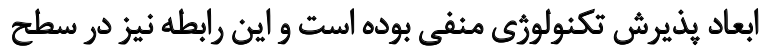

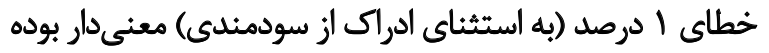

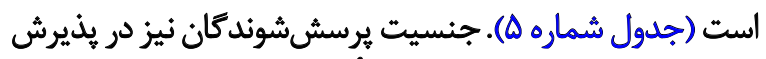

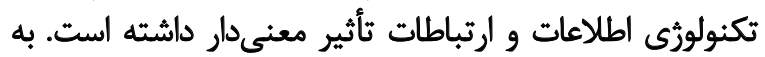

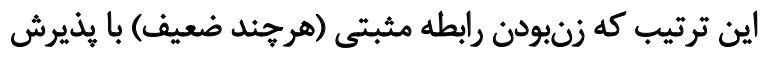

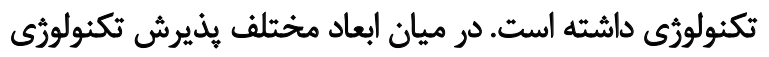

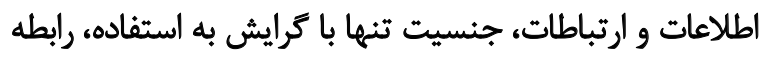

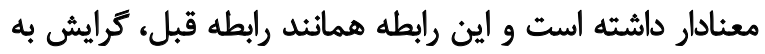
استفاده از تكنولورى اطلاعات و ارتباطات در ميان زنان رانئ رانشان مي دهل.

بر اساس نتايج بهدست آمده، مشاهده مي رشود سطح تحصيلات

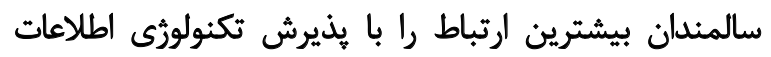

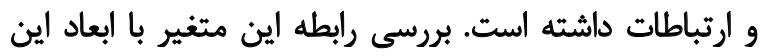

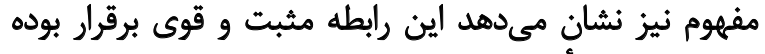

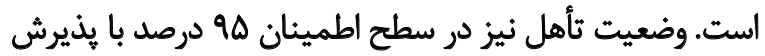

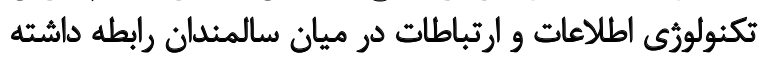

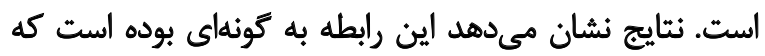
بذيرش تكنولوزى در ميان سالمندانى كه همسر داشتهاند، بيشتر بوده است. در ميان ابعاد اين مفهوم نيز رابطه معنادارى ميان خردممقياس هاى 


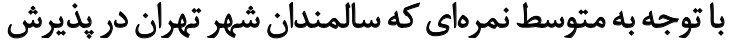

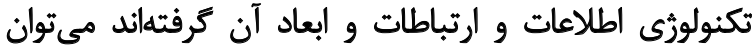

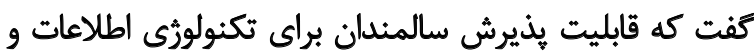

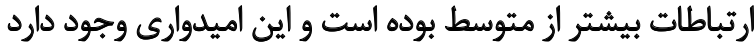

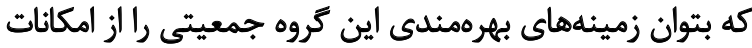

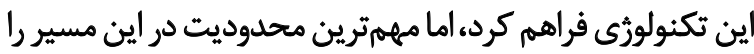

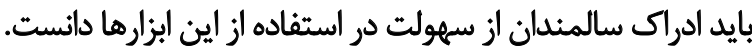

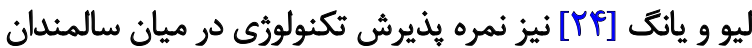

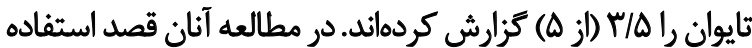

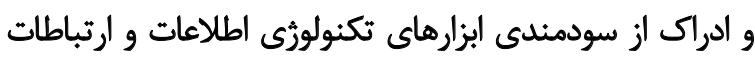

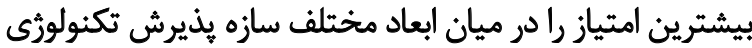

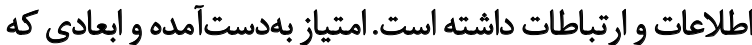

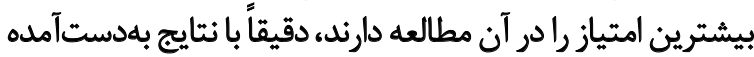

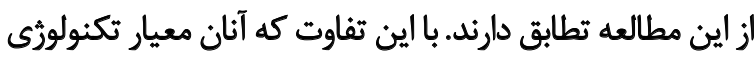

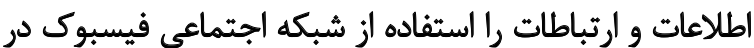

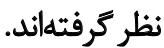

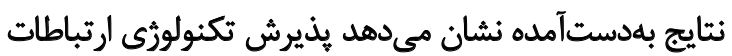

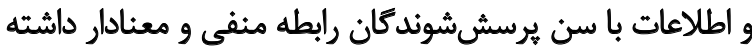

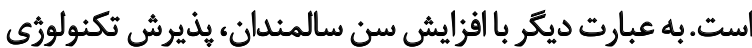

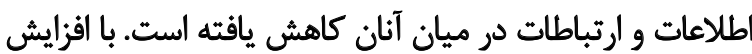

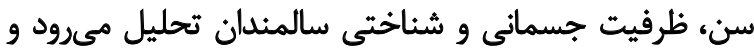

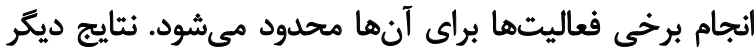

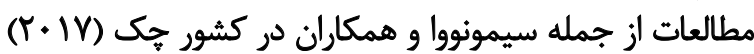

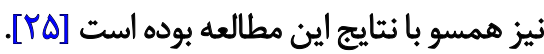

مشاهده شد كه بذيرش تكثولورثى با وضعيت سلامت عمومى ني

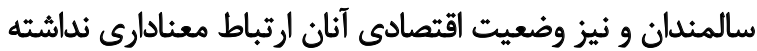

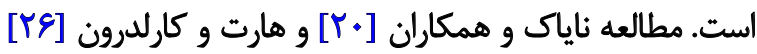

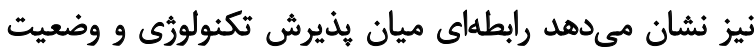

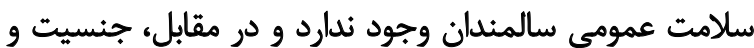

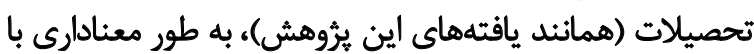

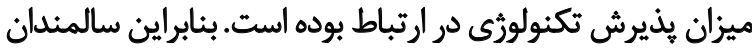

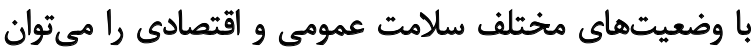

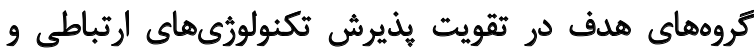

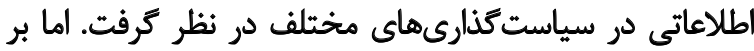

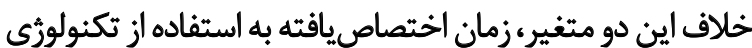

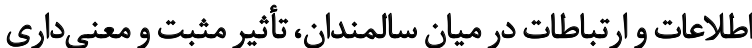
در يذيرش تكنولوزى از سوى آنان داشته است.

در مطالعه ناياك و همكاران اين يافته اثر محرك افزايش ضريب نفوذ تكنولورى اطلاعات و ارتباطات در ميان إنان سالمندان

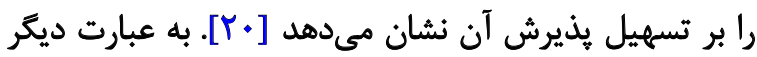

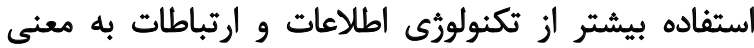

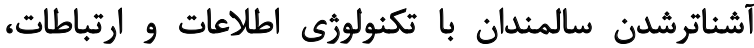

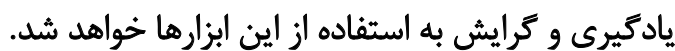

سالمندان به كوشىهاى هوشمند موبايل و اينترنت دسترسى إسى

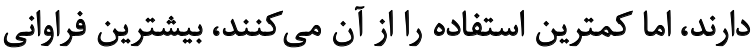
را ميان ياسخها (ז/ع دار درصد) داشته است.

نتايج جدول شماره \& نشان مىدهد يذيرش تكنولورى با

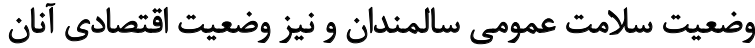

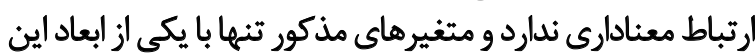

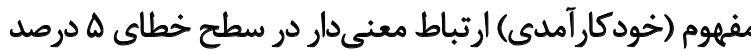

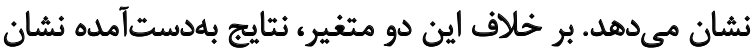

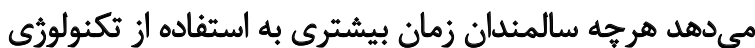

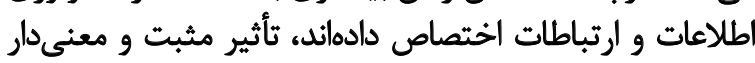
بيشترى در بذيرش تكنولوزى از سوى آنان داشته است.

ث

نتايج بهدستآمده نشان مىدهد VV/9 درصد سالمندان

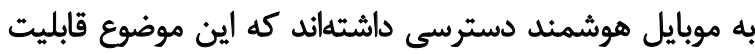

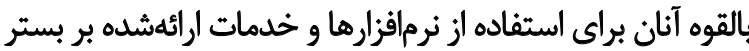

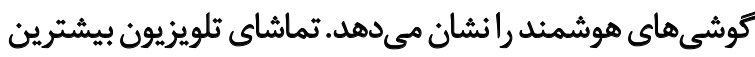

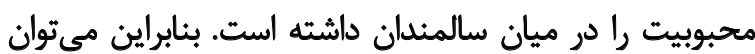

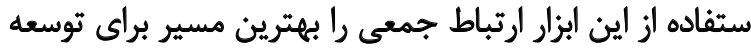

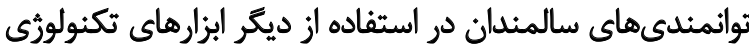

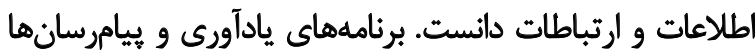

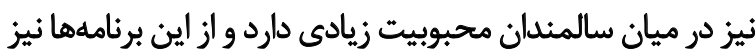

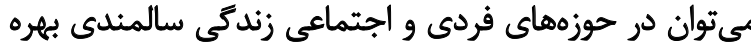

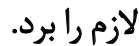

يافتههاى يزووهش نشان مى دهد نبود احساس نياز، نبود علاقه

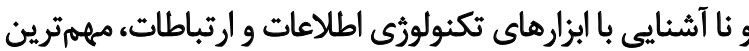

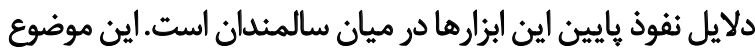

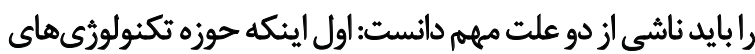

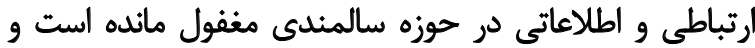

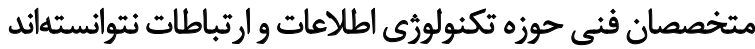

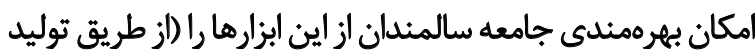

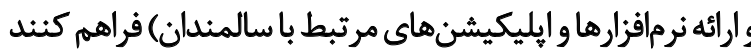

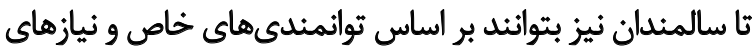
ويزٔه، از اين ابزارها سود جويند.

به علاوه مشاهده ميشود انكيزهاى ميان سالمندان براى

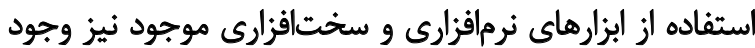

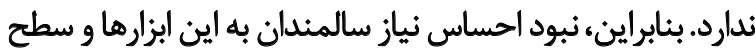

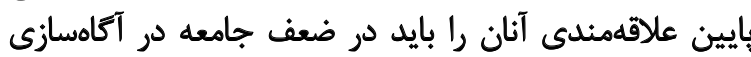

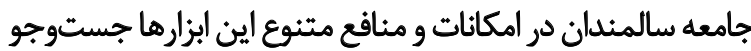

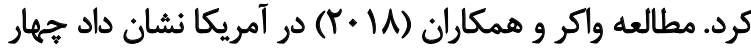

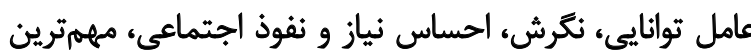

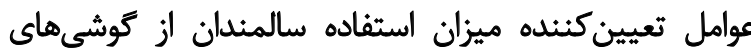

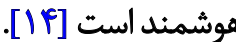




\section{ملاحظات اخلاقى \\ يبيروى از اصول اخلاق بئوهش}

اين مطالعه ثأييديه كميته اخلاق دانشكاه علوم بهزيستى و

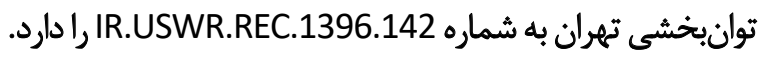

$$
\text { حامى مالى }
$$

تأمين مالى اين بروهش را معاونت محترم يُوهشى دانشعاه

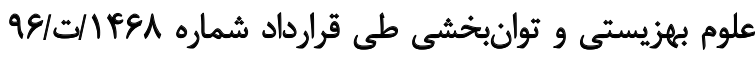

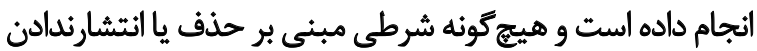

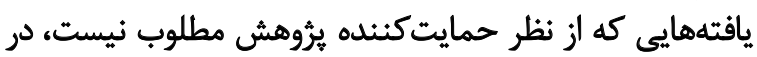

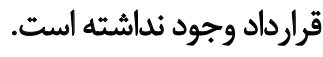

$$
\text { مشاركت ثويسندكًان }
$$

مفهوميردازى: مهدى باسخا؛ روششيناسى: مهدى باسخا،

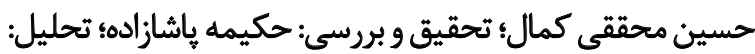

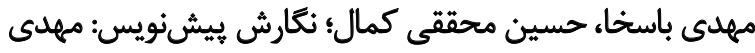

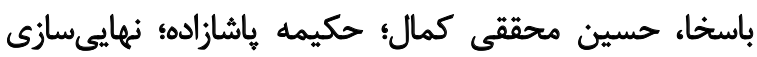

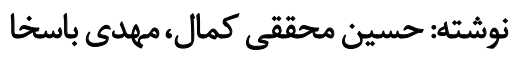

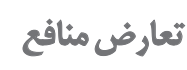

بنا به الظهار نويسندكان، در اين مقاله هيجّونه تعارض منافعى

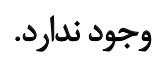

$$
\text { تشكر و قدرو دأنى }
$$

نويسندكان از معاونت يروهشى دانشكاه علوم بهزيستى و

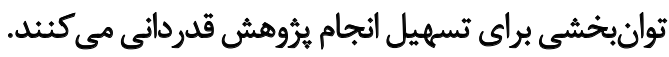

\section{نتيجلكَيرى نثهايى}

اين يُوهش به دنبال ياسخ كويى به سؤالاتى در حوزه يذيرش

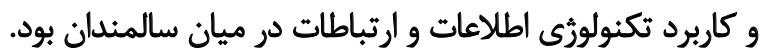

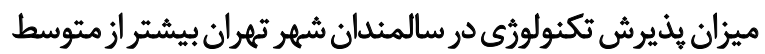

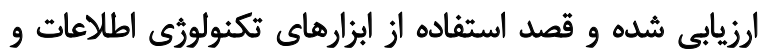

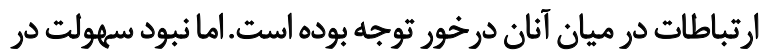

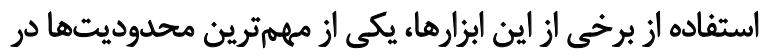

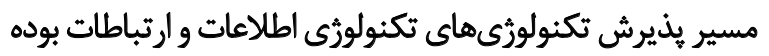

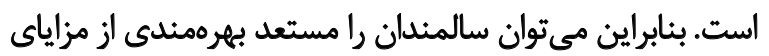

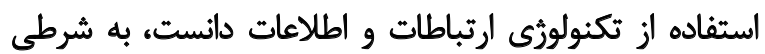

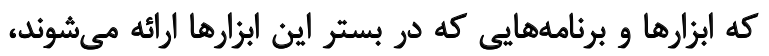

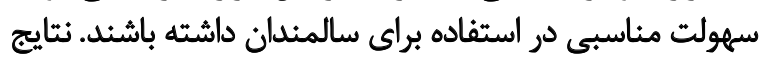

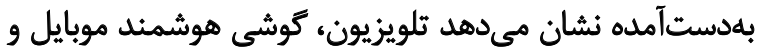

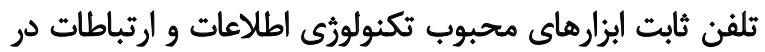
ميان سالمندان بوده است.

درصد زياد سالمندانى كه از گوشىهاى هوشمند موبايل

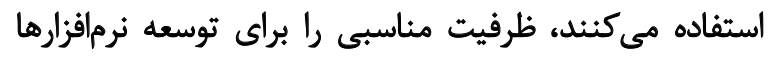

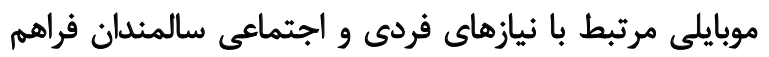

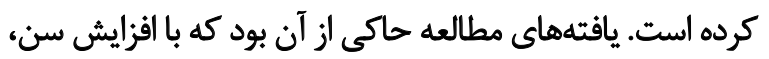

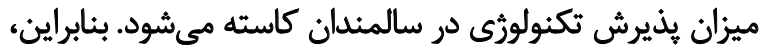

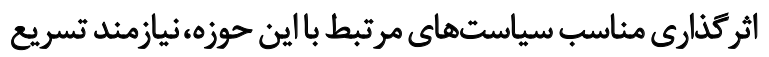

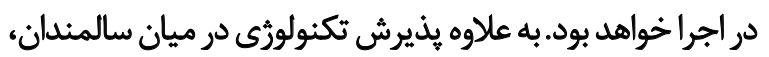

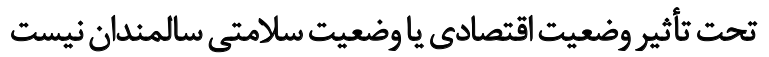

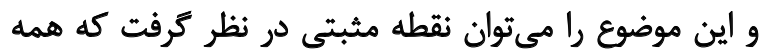

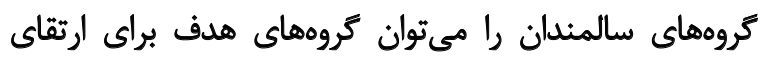

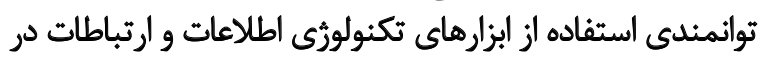

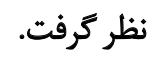

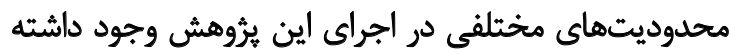

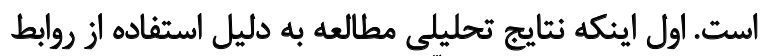

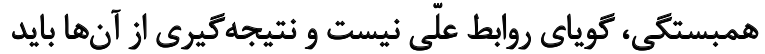

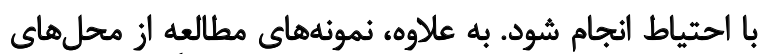

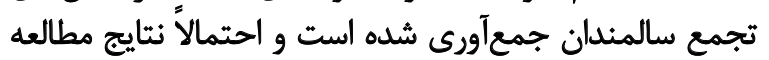

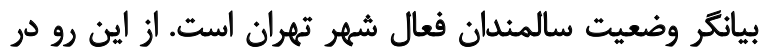

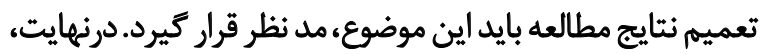

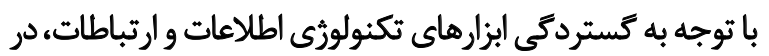

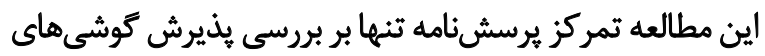

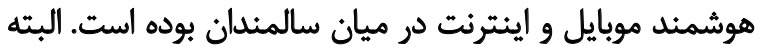

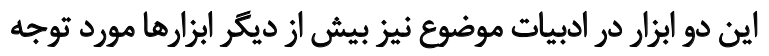

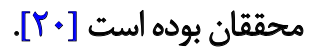




\section{References}

[1] McCausland L, Falk NL. From dinner table to digital tablet: Technology's potential for reducing loneliness in older adults. Journal of Psychosocial Nursing and Mental Health Services. 2012; 50(5):22-6. [DOI:10.3928/02793695-20120410-01] [PMID]

[2] Lin L, Xu L, Huang Y, Xiang Y, He X. On exploiting priority relation graph for reliable multi-path communication in mobile social networks. Information Sciences. 2019; 477:490-507. [DOI:10.1016/j.ins.2018.10.035]

[3] Guryanova A, Astafeva N, Filatova N, Khafiyatullina E, Guryanov N. Philosophical problems of information and communication technology in the process of modern socio-economic development. In: Shakhovska N, editor. Advances in Intelligent Systems and Computing. Berlin: Springer International Publishing; 2019. [DOI:10.1007/978-3-319-90835-9_115]

[4] $\mathrm{Ng} \mathrm{CH}$. Motivation among older adults in learning computing technologies: A grounded model. Educational Gerontology. 2007; 34(1):1-14. [DOI:10.1080/03601270701763845]

[5] McMurtrey ME, Zeltmann SM, Downey JP, McGaughey RE. Seniors and technology: Results from a field study. Journal of Computer Information Systems. 2011; 51(4):22-30.

[6] Dogruel L, Joeckel S, Bowman ND. The use and acceptance of new media entertainment technology by elderly users: Development of an expanded technology acceptance model. Behaviour \& Information Technology. 2015; 34(11):1052-63. [DOI:10.1080/0144 929X.2015.1077890]

[7] Statistical Center of Iran. [Iran statistical yearbook (Persian)]. Tehran: Statistical Centre of Iran; 2015.

[8] Rogers EM. Diffusion of innovations. New York City: Simon and Schuster; 2010

[9] Fishbein M, Ajzen I. Belief, attitude, intention and behavior: An introduction to theory and research. Boston: Addison-Wesley; 1975.

[10] Ajzen I. From intentions to actions: A theory of planned behavior. In: Weiner B, editor. Springer Series in Social Psychology. Berlin: Springer; 1985.

[11] Venkatesh V, Davis FD. A theoretical extension of the technology acceptance model: Four longitudinal field studies. Management Science. 2000; 46(2):186-204. [DOI:10.1287/ mnsc.46.2.186.11926]

[12] Legris P, Ingham J, Collerette P. Why do people use information technology? A critical review of the technology acceptance model. Information \& Management. 2003; 40(3):191-204. [DOI:10.1016/ S0378-7206(01)00143-4]

[13] Chen K, Chan AH. A review of technology acceptance by older adults. Gerontechnology. 2011; 10(1):1-12. [DOI:10.4017/ gt.2011.10.01.006.00]

[14] Walker BA, Azzarito N, Brown K, Burchfield D, Eberly K, Meert N, et al. Exploring the fit between older adults and smartphone use to inform design and practical application. Gerontechnology. 2018; 17:83s. [DOI:10.4017/gt.2018.17.s.082.00]

[15] Klimova B, Poulova P. Older people and technology acceptance. Paper presented at: International Conference on Human Aspects of IT for the Aged Population. 01 June 2018; Las Vegas, United State.
[16] Dupuy L, Consel C, Sauzéon H. Self determination-based design to achieve acceptance of assisted living technologies for older adults. Computers in Human Behavior. 2016; 65:508-21. [DOI:10.1016/j.chb.2016.07.042]

[17] Sun Y, McLaughlin ML, Cody MJ. Using the smartphone to support successful aging: Technology acceptance with selective optimization and compensation among older adults. In: Scimago Journal \& Country Rank. Lecture Notes in Computer Science Berlin: Springer Verlag; 1973.

[18] Kowal P, Peachey K. Indicators for the minimum data set project on ageing: a critical review in sub-Saharan Africa. Geneva: World Health Organization; 2001.

[19] Wiklund Axelsson SA, Melander Wikman A, Näslund A, Nyberg L. Older people's health-related ICT-use in Sweden. Gerontechnology. 2013; 12(1):36-43. [DOI:10.4017/gt.2013.12.1.010.00]

[20] Nayak LU, Priest L, White AP. An application of the technology acceptance model to the level of Internet usage by older adults. Universal Access in the Information Society. 2010; 9(4):367-74 [DOI:10.1007/s10209-009-0178-8]

[21] Gustafson DH, McTavish F, Mahoney JE, Johnson RA, Lee JD, Quanbeck A, et al. The effect of an Information and Communication Technology (ICT) on older adults' quality of life: Study protocol for a randomized control trial. Trials. 2015; 16(1):191. [DOI:10.1186/s13063-015-0713-2] [PMID] [PMCID]

[22] Rafieian M, Shali M. [Spatial analysis of development levels in Tehran (Persian)]. Modares Humanities. 2014; 16(4):25-49.

[23] Basakha M, Mohaqeqi Kamal SH. The factors affecting the acceptance of ICT among Tehran elderly. Iranian Research Center On Aging. University of Social Welfare and Rehabilitation Sciences; 2018.

[24] Liu CJ, Yang SC. Using the technology acceptance model to examine seniors' attitudes toward Facebook. International Scholarly and Scientific Research \& Innovation. 2014; 8(6):1012-7.

[25] Šimonová I, Klímová B, Poulová P, Pražák P. The use of ICT devices by older people with a special focus on their type and respondents> age: A Czech case study. Educational Gerontology. 2017; 43(12):641-9. [DOI:10.1080/03601277.2017.1386351]

[26] Heart T, Kalderon E. Older adults: Are they ready to adopt health-related ICT? International Journal of Medical Informatics. 2013; 82(11):e209-e31. [DOI:10.1016/j.ijmedinf.2011.03.002] [PMID] 
This Page Intentionally Left Blank 